\title{
Should Younger Siblings of Peanut-Allergic Children Be Assessed by an Allergist before Being Fed Peanut?
}

\author{
Joel J. Liem, MD, FRCPC, Saiful Huq, BSc, Anita L. Kozyrskyj, PhD, and Allan B. Becker, MD, FRCPC
}

\begin{abstract}
The objective of this study was to determine the risk of peanut allergy in siblings of peanut-allergic children. In 2005-2006, 560 households of children born in 1995 in the province of Manitoba, Canada, were surveyed. The index children (8- to 10-year-olds) were assessed by a pediatric allergist and had skin-prick testing and/or capRAST for peanut allergy. Surveys were completed by parents for siblings to determine the presence of peanut allergy. Of 560 surveys, 514 (92\%) were completed. Twenty-nine (5.6\%) index children were peanut allergic. Fifteen of $900(1.7 \%)$ siblings had peanut allergy. Four of $47(8.5 \%)$ were siblings of peanut-allergic children and 11 of $853(1.3 \%)$ were siblings of non-peanut-allergic children. The risk of peanut allergy was markedly increased in siblings of a peanut-allergic child (odds ratio 6.72, 95\% confidence interval 2.04-22.12). Siblings of peanut-allergic children are much more likely to be allergic to peanut. An allergy assessment by a qualified allergist should be routinely recommended before feeding peanut to these children.
\end{abstract}

Key words: allergy tests, cohort study, odds ratio, peanut allergy, siblings

$T$ here has been a dramatic increase in food allergy and other atopic conditions over the past decade or more, ${ }^{1,2}$ with the prevalence of peanut allergy increasing from $0.5 \%^{3}$ a decade ago to between 1.0 and $1.8 \%{ }^{4-6}$ Peanut allergy is the most common cause of fatal and near-fatal food-related anaphylaxis. ${ }^{7-9}$ Parents with a peanut-allergic child often have a great deal of stress in attempting to ensure a peanut-free environment in the home, school, and play environments to prevent a life-threatening reaction. ${ }^{10} \mathrm{~A}$ common question

Joel J. Liem: Windsor Allergy Asthma Education Centre, Southwestern Ontario Medical Education Network, Windsor, ON; Saiful Huq: Manitoba Institute of Child Health, Winnipeg, MB; Anita L. Kozyrskyj: Departments of Community Health Sciences and Pediatrics and Child Health, Faculty of Medicine, National Training Program in Allergy and Asthma, University of Manitoba, Winnipeg, MB; and Allan B. Becker: Section of Allergy and Clinical Immunology, Department of Pediatrics and Child Health, Manitoba Institute of Child Health, National Training Program in Allergy and Asthma, University of Manitoba, Winnipeg, MB.

Sources of funding: Canadian Institutes of Health Research; Canadian Allergy, Asthma and Immunology Foundation; Manitoba Institute of Child Health, Biology of Breathing Theme; National Training Program in Allergy and Asthma; D. Elaine Andison Foundation; and AllerGen-Allergy Gene Environment Network of the Networks of Centre of Excellence.

Correspondence to: Allan Becker, MD, FRCPC, Section of Allergy and Clinical Immunology, Department of Pediatrics and Child Health, Room AE101, 820 Sherbrook Street, Winnipeg, MB R3A 1R9; e-mail: becker@cc.umanitoba.ca.

(C) The Canadian Society of Allergy, Asthma and Clinical Immunology

DOI 10.2310/7480.2008.00017 parents ask is whether there is an increased risk of a sibling also developing a life-threatening allergy to peanut.

Traditionally, allergists do not perform testing to foods before an individual has had an apparent adverse reaction to that food. The reason stems from the risk of finding sensitization to a food (ie, evidence of the presence of allergen-specific IgE) but not necessarily "allergy" (ie, having a systemic reaction). Routine "panel testing" to foods is not recommended by the American Academy of Allergy, Asthma and Immunology or the American College of Allergy, Asthma and Immunology. The rate of asymptomatic sensitization to foods in the general population can be as high as 30 to $50 \%$, yet these individuals are not truly allergic. ${ }^{11-13}$

We sought to determine whether there is an increased risk for a peanut-allergic child to have a sibling with a peanut allergy. We asked whether an allergy assessment by a qualified allergist of a younger sibling of a peanut-allergic child might be a prudent approach prior to that child's first anticipated exposure to peanut.

\section{Methods}

The SAGE (Study of Asthma, Genes and the Environment) project is a case-control cohort study focused on the 1995 Manitoba Birth Cohort. Approximately 14,000 children were born in the province of Manitoba, Canada, and still living in the province in 2002. In 2001-2002, a child health and home environment questionnaire was sent to each household. It contained questions regarding the presence of asthma, food 
allergy, and other atopic conditions in the child. From the 3,615 returned surveys during 2003-2005, we assembled an asthma case-control cohort of 723 children (now aged 8-10 years).

In addition to a focus on asthma, a pediatric allergist (J.L. or A.B.) assessed the children for food allergy. With respect to food allergy, the clinical history included questions regarding the type of food identified, timeline of the reaction, symptoms of the reaction (eg, hives, cough, wheeze, diarrhea, vomit, loss of consciousness), severity of the reaction, and management of the reaction (ie, emergency room visit, antihistamines, epinephrine). The pediatric allergist clinical assessment for peanut allergy was blinded to skin testing and capRast results.

Skin testing to peanut (epicutaneous method) was performed on 603 children. Children sensitized to peanut had blood drawn for measurement of peanut-specific IgE by fluorenzymeimmunoassay (FEIA), generally known as capRAST. In consideration of the child's history (ie, severity of the initial reaction, presence of eczema or asthma), if the capRAST was sufficiently low $(\leq 2.0 \mathrm{kUa} / \mathrm{L})$, an oral food challenge was offered to determine true allergic status. ${ }^{14}$

\section{Index Cases of Peanut Allergy}

From among the children in the nested asthma case-control cohort (SAGE), a pediatric allergist diagnosed peanut allergy with current evidence of peanut-specific IgE (in vitro or in vivo) and/or failed peanut challenge for those children with low levels of peanut-specific IgE as noted above.

\section{Sensitized but Not Peanut Allergic}

From among the children in the cohort, the child is skin test positive to peanut but able to tolerate peanut without an allergic reaction.

\section{Index Controls (No Peanut Allergy)}

The child eats peanut products and is skin test negative.

\section{Assessment of Siblings}

After assessment of index children, a survey was distributed to the parents of both cases and controls. This survey asked the following questions with regard to the index child's siblings: (1) Do your child's siblings have any food allergies? (please name the food). If yes, (i) Was he/she diagnosed by an allergist? (What is the allergist's name?); (ii) Was he/she skin tested to that food? (iii) Was a blood test sent for that food? (capRAST); (iv) Does he/she carry an epinephrine auto-injector (EpiPen or Twinject)?
Based on the questionnaire, diagnoses of peanut allergy were made as follows: parental report that the sibling has peanut allergy and that the child was assessed as peanut allergic by a board-certified allergist in the province of Manitoba in the past 5 years ( 10 allergists practiced in the province during that time), and the child currently carries an epinephrine auto-injector. The allergists of those siblings were contacted to confirm the diagnosis of true peanut allergy; however, this was not a requirement for diagnosis.

The study was approved by the Health Research Ethics Board at the University of Manitoba and the Health Information Privacy Committee of Manitoba.

\section{Statistical Analysis}

Statistical analysis was performed with SAS software (SAS Institute, Cary, NC). Odds ratios with $95 \%$ confidence intervals (CIs) were calculated to determine the risk of a sibling of a peanut-allergic child having a peanut allergy when compared with the sibling of a non-peanut-allergic child. Children who were sensitized to peanut but not clinically allergic were excluded from analysis. Stratification by older versus younger sibling was performed. Multivariate analysis was performed to adjust for parental history of asthma. In the younger sibling stratification, adjustments were made for a physician diagnosis of asthma in the index child and parental history of asthma.

\section{Results}

From the SAGE case-control cohort, 560 of 603 children tested to peanut were contacted to fill out the Sibling Food Allergy survey. Forty-three families had completed the primary study before this survey was introduced. Of 560 index families, 514 (92\%) completed the survey. Twenty-nine (5.6\%) index children were defined as peanut-allergic (cases), and eight index children were sensitized but not allergic. Four hundred fifty index children were not peanut allergic or sensitized (controls). The demographics of the cases and controls are shown in Table 1. Table 2 shows the supporting test results to confirm peanut-allergic diagnoses in index children.

Of the 514 index children, 27 did not have siblings. There were 900 siblings of the index children (excluding siblings of children who were sensitized to peanut but not allergic). Fifteen (1.7\%) siblings had peanut allergy: 4 of $47(8.5 \%)$ in the case group and 11 of $853(1.3 \%)$ in the control group. Table 3 shows the evidence of peanut allergy in the siblings. We were able to confirm the diagnosis of peanut allergy in 14 of the siblings.

Eight $(1.5 \%)$ children were sensitized to peanut by 
Table 1. Demographics of Peanut and Non-Peanut-Allergic Children

\begin{tabular}{lcccc}
\hline Index Children & Peanut Allergic & Non-Peanut Allergic & Sensitized & No Siblings \\
\hline Number & 29 & 450 & 8 & 27 \\
Male:female & $16: 13$ & $248: 202$ & $5: 3$ & $18: 9$ \\
Urban:rural:FN & $20: 8: 1$ & $247: 160: 43$ & $0: 6: 2$ & $18: 9: 0$ \\
Parental history of asthma & 12 & 150 & 6 & 8 \\
Total number of siblings & $47(29: 18)$ & $853(485: 368)$ & $9(4: 5)$ & - \\
(older:younger) & & & & \\
\hline
\end{tabular}

FN $=$ First Nations

Table 2. Diagnoses of Peanut Allergy in Index Children (Cases)

\begin{tabular}{|c|c|c|c|c|}
\hline Case & $\begin{array}{l}\text { Peanut Skin-Prick Test Mean } \\
\text { Wheal Diameter }(\mathrm{mm})\end{array}$ & $\begin{array}{c}\text { Peanut-Specific } \\
\operatorname{IgE}(k U a / L)\end{array}$ & $\begin{array}{l}\text { Oral Challenge to } \\
\text { Peanut Butter* }\end{array}$ & $\begin{array}{c}\text { Sibling with } \\
\text { Peanut Allergy? }\end{array}$ \\
\hline 1 & NA & 81.1 & NA & No \\
\hline 2 & NA & 5.2 & NA & No \\
\hline 3 & NA & 42.8 & NA & No \\
\hline 4 & 13 & $>100$ & NA & No \\
\hline 5 & NA & $>100$ & NA & No \\
\hline 6 & 10 & $>100$ & NA & Yes \\
\hline 7 & 9 & $>100$ & NA & Yes \\
\hline 8 & 0 & $>100$ & NA & No \\
\hline 9 & 7 & $>100$ & NA & Yes \\
\hline 10 & 0 & 1 & Failed oral challenge $^{\dagger}$ & No \\
\hline 11 & 5 & 5.7 & NA & No \\
\hline 12 & 6 & 1.1 & Refused oral challenge & No \\
\hline 13 & 4 & 16.9 & NA & No \\
\hline 14 & 5 & $>100$ & NA & No \\
\hline 15 & 10 & 29 & NA & No \\
\hline 16 & 9 & 41 & NA & No \\
\hline 17 & 11 & $>100$ & NA & Yes \\
\hline 18 & 10 & 1.4 & Offered but lost to follow-up & No \\
\hline 19 & 7 & 0.8 & Failed oral challenge $^{\dagger}$ & No \\
\hline 20 & 8 & 2.09 & NA & No \\
\hline 21 & 17 & NA & NA & No \\
\hline 22 & 10 & $>100$ & NA & No \\
\hline 23 & 8 & 0.72 & Failed oral challenge $^{\dagger}$ & No \\
\hline 24 & 15 & 80.2 & NA & No \\
\hline 25 & 7 & $>100$ & NA & No \\
\hline 26 & 8 & 17.6 & NA & No \\
\hline 27 & 6 & $<0.35$ & Lost to follow-up & No \\
\hline 28 & 8 & 28.2 & NA & No \\
\hline 29 & 10 & 36.7 & NA & No \\
\hline
\end{tabular}

$\mathrm{NA}=$ not available

${ }^{*}$ In general, oral food challenges to peanut were offered to those with a capRast $<2.0 \mathrm{kUa} / \mathrm{L} .{ }^{14}$

All children had a convincing history of peanut allergy prior to performing skin-prick testing \pm capRAST.

${ }^{\dagger}$ An oral challenge to peanut was performed in the hospital and the child had an adverse reaction.

skin-prick test but not allergic (able to eat peanuts without an adverse reaction). None of their siblings had a peanut allergy.

The odds ratio of a current peanut-allergic child at the age of 9 to 10 years having a sibling also with a peanut allergy is 7.12 (95\% CI 2.18-23.28). After adjusting for a parental history of asthma, the odds ratio is 6.72 (95\% CI 2.04-22.12) (Table 4).

If an older sibling of the index child had peanut allergy, the adjusted odds ratio of the index child having a peanut al- lergy is 6.31 (95\% CI 1.20-33.23). If the index child had peanut allergy, the adjusted odds ratio of a younger sibling also having peanut allergy is 11.76 (95\% CI 2.46-56.27).

\section{Discussion}

Using a cohort study, we have shown that the sibling of a peanut-allergic child has a dramatically increased risk of developing peanut allergy. This risk is nearly 7 -fold greater than those who do not have a sibling with peanut allergy, with 
Table 3. Peanut-Allergic Siblings of Index Children

\begin{tabular}{|c|c|c|c|}
\hline Siblings of & $\begin{array}{l}\text { Index Child } \\
\text { Sibling from } \\
\text { Table } 2\end{array}$ & $\begin{array}{l}\text { Confirmed } \\
\text { Diagnosis } \\
\text { with Allergist }\end{array}$ & $\begin{array}{l}\text { Evidence of IgE SPT or } \\
\text { capRast }\end{array}$ \\
\hline \multicolumn{4}{|l|}{ Cases } \\
\hline 1 & 6 & Yes & capRast > $100 \mathrm{kUa} / \mathrm{L}$ \\
\hline 2 & 7 & Yes & capRast $>100 \mathrm{kUa} / \mathrm{L}$ \\
\hline 3 & 9 & Yes & capRast $>100 \mathrm{kUa} / \mathrm{L}$ \\
\hline 4 & 17 & Yes & $\begin{array}{l}\text { SPT mean wheal diameter } \\
\quad 21 \mathrm{~mm}\end{array}$ \\
\hline \multicolumn{4}{|l|}{ Controls } \\
\hline 1 & NA & Yes & $\begin{array}{l}\text { SPT mean wheal diameter } \\
21 \mathrm{~mm}\end{array}$ \\
\hline 2 & NA & Yes & capRast $>100 \mathrm{kUa} / \mathrm{L}$ \\
\hline 3 & NA & Yes & $\begin{array}{l}\text { Large SPT+ (no } \\
\quad \text { measurement recorded) }\end{array}$ \\
\hline 4 & NA & Yes & $\begin{array}{l}\text { SPT mean wheal diameter } \\
\quad 8 \mathrm{~mm}\end{array}$ \\
\hline 5 & NA & Yes & capRast $=90.3 \mathrm{kUa} / \mathrm{L}$ \\
\hline 6 & NA & Yes & capRast $=22.8 \mathrm{kUa} / \mathrm{L}$ \\
\hline 7 & NA & Yes & $\begin{array}{l}\text { SPT mean wheal diameter } \\
\qquad 14 \mathrm{~mm}\end{array}$ \\
\hline 8 & NA & Yes & $\begin{array}{l}\text { SPT: } 4+\text { reaction } \\
\text { (pseudopods) }\end{array}$ \\
\hline 9 & NA & No & Not confirmed \\
\hline 10 & NA & Yes & capRast $>100 \mathrm{kUa} / \mathrm{L}$ \\
\hline 11 & NA & Yes & $\begin{array}{l}\text { capRast }=2.3 \mathrm{kUa} / \mathrm{L} ; \text { no oral } \\
\text { challenge }\end{array}$ \\
\hline
\end{tabular}

capRAST = FEIA for peanut-specific IgE; NA = not available; SPT = skin-prick test. *Allergist diagnosis included a definitive history of an adverse reaction to ingestion of peanut and evidence (in vivo or in vitro) of IgE toward peanut. Only control 9 was not confirmed.

Table 4. Risk of Peanut Allergy in Siblings of a Peanut-Allergic Child

\begin{tabular}{lllcl}
\hline $\begin{array}{l}\text { Risk of Peanut } \\
\text { Allergy in }\end{array}$ & $\begin{array}{l}\text { Unadjusted } \\
\text { Odds Ratio }\end{array}$ & $95 \%$ CI & $\begin{array}{l}\text { Adjusted } \\
\text { Odds Ratio }\end{array}$ & 95\% CI \\
\hline Any sibling $^{\text {Younger sibling }}{ }^{\dagger}$ & 7.12 & $2.18-23.28$ & $6.72^{*}$ & $2.04-22.12$ \\
Older sibling $^{\S}$ & 5.92 & $1.63-50.40$ & $11.76^{\ddagger}$ & $2.46-56.27$ \\
\hline
\end{tabular}

$\mathrm{CI}=$ confidence interval.

${ }^{*}$ Adjusted for parental history of asthma.

'If index child had a peanut allergy, risk of peanut allergy in a younger sibling.

${ }^{*}$ Adjusted for parental history of asthma and physician diagnosis of asthma in index child.

'If older sibling had a peanut allergy, risk of peanut allergy in the index child.

an almost 12 -fold increased risk for peanut allergy among younger siblings.

Emmett and colleagues examined the perceived prevalence of peanut allergy in Great Britain by using a screening survey followed by in-depth interviews with all reported sufferers from peanut allergy. ${ }^{15}$ They estimated a peanut prevalence of $0.48 \%$. Given one case in a household, the probability of another was estimated at 3.2\% - six times that in the United Kingdom $(p<.001)$. Nine of the 10 second cases in the same household were in first-degree relatives. They do not specify if these relatives were siblings. Our sevenfold increased risk is similar to their findings, except specifically for siblings.
Hourihane and colleagues examined the rates of atopic manifestations in people with peanut allergy and the prevalence of such allergy in their families by surveying 622 adults and children with reported, suspected, or known peanut allergy. ${ }^{16}$ They evaluated 50 local children (mean age 5 years) with apparent peanut allergy and compared their results with those of a general population prevalence of peanut allergy $(1.0-1.5 \%)$. In that study, the prevalence of peanut allergy in siblings of a peanut-allergic child was 7\% (3 of 39). Sicherer and colleagues evaluated 58 twin pairs (median age of 5 years) ascertained through the Food Allergy Network. ${ }^{17}$ They found a $64.3 \%$ pairwise concordance between monozygotic pairs and $6.8 \%$ concordance between dizygotic pairs. Our prevalence of $8.5 \%$ ( 4 of 47 ) among siblings is quite similar to both studies. Our study differs with the above two in that we studied a birth cohort of children all born in 1995 from across the province of Manitoba.

When we stratify our sibling cohort into younger and older siblings, we demonstrate that the younger sibling particularly has a very highly statistically significant increased risk for having a peanut allergy. Clearly, there is a genetic predisposition for peanut allergy in these families. Given the greater likelihood for a younger sibling having peanut allergy, we also question how much of a role the environment may play. As far as we are aware, there are no studies examining the impact of parental behaviour change with having a peanut-allergic child in the family. Intuitively, we would expect that parents will alter their behaviour to decrease exposure to peanut (ie, avoidance of peanut and tree nuts), particularly in the home environment. Of concern, recent human and animal literature suggests that avoidance of highly "allergenic" foods in pregnancy and early in life may actually predispose, as opposed to protect, a child to develop IgE-mediated food allergy. ${ }^{18-20}$

Another finding from our study is the fact that $22 \%$ of children with positive skin testing to peanut ( 8 of 37 children) routinely had peanut without a problem. That is, these children were sensitized, but not truly allergic. This confirms other studies that have shown that a positive skin-prick test is only "suggestive" of the presence of a clinical peanut allergy. ${ }^{1-13} \mathrm{~A}$ diagnosis of peanut allergy cannot be solely based on a skinprick test but requires a proper clinical history or additional testing to corroborate the presence of true allergy. Although we agree that indiscriminate testing for peanut allergy should not be performed, based on our findings in this study, we recommend that siblings of peanut-allergic children should be assessed by a qualified allergist and, potentially, have appropriate skin testing.

Of note, two children in our cohort diagnosed by the pediatric allergist as allergic to peanut were skin test negative. One 
child had a strongly positive blood test for peanut-specific IgE (capRAST $>100 \mathrm{kUa} / \mathrm{L}$ ), and the other, with a positive but low level of peanut-specific IgE (capRAST of $1.0 \mathrm{kUa} / \mathrm{L}$ ), failed an oral challenge. Neither of these children had a peanut-allergic sibling. This points out the value of measuring allergen-specific IgE in vitro (eg, capRAST) and performing proper food challenges as important tools to aid in the diagnosis of true food allergy. ${ }^{14}$

Only one sibling (control 9) was unconfirmed by an allergist. However, the history was quite convincing of an IgEmediated allergy to peanut allergy. If this sibling was not used in the analysis, the odds ratio would be even higher than that stated.

One limitation to our study is that we used the SAGE casecontrol cohort for this analysis. This is a high-risk cohort with respect to asthma as the purpose of the primary study is to investigate gene and environmental factors that may play a role in the development of asthma and allergy. Thus, our control group may be skewed toward being more allergic than the general population. Even so, these would be the patients one would expect to see in an allergy clinic. However, if the control group is biased toward an atopic predisposition, this may actually also overestimate peanut prevalence in the siblings of the control group. In spite of this, the prevalence of peanut allergy in our control group is similar to that reported in Canada and North America. ${ }^{5,6}$

Ideally, the oral food challenge is the best diagnostic test to determine true peanut allergy in children. In Manitoba, along with other aspects of history (ie, severity of initial reaction, presence of eczema or asthma), allergists use a capRAST value of $<2.0 \mathrm{kUa} / \mathrm{L}$ to decide if a child should undergo an oral challenge. ${ }^{14}$ Sampson found that a capRAST $>15 \mathrm{kUa} / \mathrm{L}$ would provide a $95 \%$ predictive decision point to determine true allergy. ${ }^{21}$ Thus, we realize that some of our index cases (eg, cases $2,11,12,18,20$, and 27) and sibling control 11 may not be truly allergic. All of these children had good histories of an allergic reaction yet did not undergo an oral challenge. This is one limitation that may have overestimated our peanut prevalence.

A prospective long-term follow-up study of siblings of peanut-allergic children would be the best method to determine whether the skin test or capRAST should be used as a screening tool in siblings. One concern of screening siblings prior to feeding could cause either unnecessary avoidance or challenge procedures. Our study shows that there is an increased risk in peanut allergy in siblings of peanut-allergic children, which would suggest that screening of siblings is important. However, future studies should clarify proper cutoff points (for capRAST or skin-prick test wheal size) to aid in determination of risk of an oral challenge in these siblings.
In summary, we have shown that siblings of peanutallergic children have a significantly increased risk of also developing a peanut allergy. We recommend that siblings born into a family with a peanut-allergic child be assessed for peanut allergy by a qualified allergist (who may perform skin-prick testing or measurement of allergen-specific IgE by capRAST or other technique) prior to being fed this food. An oral challenge in a controlled setting may be required. Future research must examine gene-environment interactions predisposing children to this increasingly common and potentially fatal food allergy.

\section{Acknowledgements}

A special thanks to the SAGE (Study of Asthma, Genes and the Environment) team, including Rishma Chooniedass, Miriam Clement, Donna Everette, Brenda Gerwing, Shamima Huq, Marilyn Lilley, Tanya Lilley-Chan, Ingrid Loewen, Mellissa Moyen, Rasheda Rabbani, Diane Stewart, Michelle Tillett, and John Weselake.

\section{References}

1. Sampson H. Adverse reactions to foods. In: Adkinson NF Jr, Bochner $\mathrm{B}$, Yunginger J, et al, editors. Middleton's allergy principles \& practice. 6th ed. Philadelphia: Mosby; 2003. p. 1619-43.

2. von Mutius E, Martinez F. Natural history, development, and prevention of allergic disease in childhood. In: Adkinson NF Jr, Bochner B, Yunginger J, et al, editors. Middleton's allergy principles \& practice. 6 th ed. Philadelphia: Mosby; 2003. p. 1169-74.

3. Tariq SM, Stevens M, Matthews S, et al. Cohort study of peanut and tree nut sensitisation by age of 4 years. BMJ 1996;313:514-7.

4. Hourihane JO, Aiken R, Briggs R, et al. The impact of government advice to pregnant mothers regarding peanut avoidance on the prevalence of peanut allergy in United Kingdom children at school entry. J Allergy Clin Immunol 2007;119:1197-202.

5. Kagan RS, Joseph L, Dufresne C, et al. Prevalence of peanut allergy in primary-school children in Montreal, Canada. J Allergy Clin Immunol 2003;112:1223-8.

6. Sicherer SH, Munoz-Furlong A, Sampson HA. Prevalence of peanut and tree nut allergy in the United States determined by means of a random digit dial telephone survey: a 5-year follow-up study. J Allergy Clin Immunol 2003;112:1203-7.

7. Sampson HA, Mendelson L, Rosen JP. Fatal and near-fatal anaphylactic reactions to food in children and adolescents. N Engl J Med 1992;327:380-4.

8. Sicherer SH, Furlong TJ, Munoz-Furlong A, et al. A voluntary registry for peanut and tree nut allergy: characteristics of the first 5149 registrants. J Allergy Clin Immunol 2001;108:128-32.

9. Yocum MW, Butterfield JH, Klein JS, et al. Epidemiology of anaphylaxis in Olmsted County: a population-based study. J Allergy Clin Immunol 1999;104(2 Pt 1):452-6.

10. Avery NJ, King RM, Knight S, Hourihane JO. Assessment of quality of life in children with peanut allergy. Pediatr Allergy Immunol 2003; $14: 378-82$. 
11. Bock SA, Atkins FM. Patterns of food hypersensitivity during sixteen years of double-blind, placebo-controlled food challenges. J Pediatr 1990;117:561-7.

12. Rance F, Juchet A, Bremont F, Dutau G. Correlations between skin prick tests using commercial extracts and fresh foods, specific IgE, and food challenges. Allergy 1997;52:1031-5.

13. Sampson HA, Albergo R. Comparison of results of skin tests, RAST, and double-blind, placebo-controlled food challenges in children with atopic dermatitis. J Allergy Clin Immunol 1984;74:26-33.

14. Perry TT, Matsui EC, Kay Conover-Walker M, Wood RA. The relationship of allergen-specific IgE levels and oral food challenge outcome. J Allergy Clin Immunol 2004;114:144-9.

15. Emmett SE, Angus FJ, Fry JS, Lee PN. Perceived prevalence of peanut allergy in Great Britain and its association with other atopic conditions and with peanut allergy in other household members. Allergy 1999;54:380-5.
16. Hourihane JO, Dean TP, Warner JO. Peanut allergy in relation to heredity, maternal diet, and other atopic diseases: results of a questionnaire survey, skin prick testing, and food challenges. BMJ 1996;313:518-21.

17. Sicherer SH, Furlong TJ, Maes HH, et al. Genetics of peanut allergy: a twin study. J Allergy Clin Immunol 2000;106(1 Pt 1):53-6.

18. Franco L, Benedetti R, Ferek GA, et al. Priming or tolerization of the B- and Th2-dependent immune response by the oral administration of OVA-DNP is determined by the antigen dosage. Cell Immunol 1998;190:1-11.

19. Liem JJ, Kozyrskyj AL, Huq SI, Becker AB. The risk of developing food allergy in premature or low-birth-weight children. J Allergy Clin Immunol 2007;119:1203-9.

20. Strid J, Thomson M, Hourihane J, et al. A novel model of sensitization and oral tolerance to peanut protein. Immunology 2004;113:293-303.

21. Sampson HA. Utility of food-specific IgE concentrations in predicting symptomatic food allergy. J Allergy Clin Immunol 2001;107:891-6. 